\title{
Imagination and the Image: A Revised Phenomenology of Imagination and Affectivity
}

\author{
By EREZ NIR \\ Bar-Ilan University, Israel
}

\begin{abstract}
In this paper I offer a critical revision of the main thematic phenomenological writings on imagination by Sartre and Edward Casey based on the following three criteria: 1. the sufficiency of their respective sui generis accounts of imagination. 2. The capacity of their respective frameworks to account for imagination's rich affectivity. 3. Their ability to provide a coherent and purely transcendental description of the difference between imagination and perception. I argue that in both Sartre and Casey the problematic aspects of their theories derive from focusing solely on the nature of the imaginative object at the expense of the imaginative experience as a whole. Using Husserl's transcripts on the subject, I suggest a new phenomenological analysis of imagination as the direct intuition of the experience of the object instead of an intuition of an object in a possible mode. I argue that in imagination the object is present in a marginal way and what is directly experienced is the object's affective form, which is an intuitive aspect of the object's value qualities. This analysis shows that the intentional presence of value qualities in objects, and the general presence of value in the world is always connected to the way we imagine objects and not the way we perceive them, and that the value of things is better to be called their imaginative structure.
\end{abstract}

\section{Introduction}

Imagination is an enigma of consciousness. Even though it is a directly given experience, just like emotion and thought, it is totally dismissed as "not real" and incapable of informing us of anything real or true. Yet, simply dismiss- 
ing imagination has its price, for we do not have the ability to stop imagining, and thus find our consciousness constantly inhabited with these "non real" contents that cloud and disrupt our comprehension of the world. Philosophy too has had this tendency to dismiss imagination. From Plato's presentation of imagination in The Republic as the lowest form of cognitive activity that hides reality, to critical Marxist theory emphasizing the role of ideology in the creation and preservation of false consciousness, philosophy has tended to see in imagination a nemesis of clarity. But even when philosophers did find an important role for imagination, it tends to receive its importance via the service it can provide to other acts of consciousness. Whether it is Descartes'mediating function between objects and ideas or the Kantian schemata that recognizes imagination as the power connecting categories and sensuality, imagination is left enslaved to the greater functions it is thought to serve and never fully recognized in its own right.

Today, flooded by virtual content, it is clearer that imagination is too central and present to be understood only as an enemy or a slave, and must be described in a way that explicates its own meaning. Transcendental phenomenology, with its ability to bracket questions of ontological reality, has a great deal of promise for creating a picture of imaginative experience that is not dismissed due to its unreality. In this paper I will show that this promise has not yet been fulfilled, and suggest a new phenomenological description of imaginative intentionality that strives directly towards this goal. My claim is that imagination is far from being simply "unreal", and when understood through its full direct experience, it is revealed as constituting critically vital aspects of existence. I will claim that our actual living experience has an imaginative structure no less than it has a physical structure, only the imaginative structure is explicitly plural and should be addressed as imaginative structures.

Some preliminary remarks. In this work, when I speak of imagination I refer to every intuitive presentation of an object that is not present, including pure mental imagery and mediated image consciousness such as pictures, films and the sort. This generalization is established in the phenomenological writing by Husserl and Sartre and even though it is criticized in analytic philosophy, it addresses imaginative experience at its essence as the mental capacity to experience the unreal. But in this phenomenological approach a new problem arises regarding this definition itself: by the transcendental bracketing of the question of real existence we lose this basic distinction of reality between imagination and perception. Therefore, a full phenomenological description of imagination should offer a new transcendental distinction between imagination and perception, one that does not rely on the classic 
distinction of actual reality but rather explains how they are experienced differently in a way that makes consciousness recognize the one as "real" and the other as not.

\section{Sartre and Casey on Imagination and Affectivity}

Sartre develops his position on the phenomenon of imagination by contrasting imagination with perception and highlighting the radically different way in which the phenomena appear to us in each case ${ }^{1}$. In perception, the object appears as incomplete, always allowing for further learning, observation, investigation and discovery ${ }^{2}$. In direct contrast to the perceptual phenomenon, imagined phenomena present themselves in their totality, arising all at once, "like a thought". A phenomenon of imagination, by its very nature, is incapable of true scrutiny. Any detail that exists "in" the imagined object must antecedently be placed there, that is, it must be antecedently intended by the subject who is imagining ${ }^{3}$.

According to Sartre, there is no imaginative object at all, rather imagination is simply an act. We do not intuit anything in imagination, rather, we only intend an object that is absent. Imagination is always experienced as nothingness, presenting nothingness at its very core, and this is the way we intuitively differentiate between imagination and perception. This ability to directly intuit nothingness through imagination is what secures our transcendence and it is here that Sartre finds the sui generis importance of imagination. Basically, our ability to directly intuit nothingness is what enables us to construct totalities, to posit a world or in Sartre's Heideggerian language "to be in the world but not of it" 4 . Hence the "imaginative object" (which is not really an object at all but only an intentional construct) proves that we can intuit nothingness, and the significance of the imagination is found in the fact that nothingness itself is profound and significant. The problem is that this significance of imagination lies in that it serves perception and thought, enabling us to experience a world.

Sartre's characterization of the phenomenon of imagination as pure nothingness leads him to account for the affectivity of imaginative experience by placing that affectivity outside of the imaginative structure itself.

${ }^{1}$ Sartre J.P., 2004, p. 4-14.

2 Ibid., p. 8-10.

${ }^{3}$ Ibid., p. 120-122.

${ }^{4}$ Ibid., p. 183. 
According to Sartre ${ }^{1}$, imagination is the experience of nothingness as seen through the annihilation of an actual object. This actual object that is "seenthrough" is called the analagon. The analogon may be physical (such as a picture described in terms of its physical, non-representational properties), it may be psychical (a sort of mental construct), or it may be both ${ }^{2}$. Affectivity is simply one modality of many possible modalities of the analogon. When we have an affective imaginative experience, it is not that nothingness is affective, rather, we are mediating our intuition of nothingness through an affective modality. Therefore, according to Sartre, affectivity is not central to the imaginative experience, rather it is simply one of the many possible modalities through which we can imagine.

Edward Casey was highly critical of Sartre and took issue with many of his points, including the heavy explanatory load placed on the analogon as well as the host of ontological problems created by it. But what was most interesting to me was Casey's articulation of the "root cause" of all the major problems in Sartre's philosophy. According to Casey, Sartre gave a completely "inadequate description of the phenomenon of imagining itself", so Casey's solution was to delve further inside the phenomenon. Despite his criticism of Sartre, Casey develops a taxonomy of imagination that bears strikingly similarities to Sartre's account. Every imaginative phenomenon possesses, according to Casey, three pairs of trait-specific characteristics: spontaneity and controlledness, self-containment and self-evidence, indeterminacy and pure possibility ${ }^{4}$. The last two pairs are what Casey calls "traitnecessary insofar as they characterize every feature of imagining without exception". Pure possibility is the highlight of Casey's investigations and imagination's importance is found as a means through which consciousness secures access to pure possibility. Thus, for Casey, the importance of imagination is found in the special way it enriches thought.

Most revealing is that Casey, unlike Sartre, does nothing to explain the rich affectivity of the imaginative experience. While his taxonomy is

\footnotetext{
${ }^{1}$ Ibid., p. 68-72.

${ }^{2}$ Sartre gives a detailed account of the many kinds of material images who function as "analagons", starting with the detailed and direct ones such as portraits and photographs and finishing with seeing shapes in clouds and coffee (Ibid., p. 17-49). It seems that the purpose of this detailed account is to show the continuity that exists between "seeing through" material images, and "seeing through" mental contents as is the case in mental imagery.

${ }^{3}$ Casey E., 1981, p. 147.

${ }^{4}$ Casey E., 2000, p. 63-103.

${ }^{5}$ Casey E., Behnke E. \& Kanata S., 1997, p. 343.
} 
thorough, affectivity is completely absent and in its place there is a reemphasis of the protean, undetermined and purely possible nature of the objects themselves. Let's imagine for a moment Casey's solution applied to a real life encounter with an imaginative experience. It's 2:00 am and your child runs screaming into your bedroom in utter terror because he has just seen a monster in his room. If your response is to interrogate your child about the specific mode through which the monster appeared - whether it was spontaneous or controlled, undetermined or clear - while sidelining the raw factual experience of the child's terror, then it is obvious that you are missing the heart of the phenomenon itself. If we cannot address the rich affectivity of the imaginative experience, we will always be left wanting. There was a time when the philosophical project of securing human freedom was paramount, but it should never be done at the expense of ignoring a central feature of the experience itself. Accounting for the rich affectivity of imaginative experience could not be more timely. Our contemporary lifeworld is overflowing with imaginative content created by new technologies, virtual worlds and creative output, of which rich affectivity is an essential component. If, by focusing on the imaginative object, we are lead further away from a clear explanatory framework for affectivity, then it seems that the imaginative object is not telling us the whole story of the imaginative experience.

\section{The Phenomenological Structure of Imagining}

When we examine the imaginative experience intuitively we are presented with a rather simple scheme: in imagination, we basically have an experience of an object that is absent. Whether the object is absent as in "not here now" or absent as in, "not really existing anywhere" matters little at this point. In terms of explaining affectivity, the problem becomes: How does an object that is absent affect us presently? What I want to suggest is that the problem I have posed is a pseudo-problem. It is from this pseudo problem that I propose my solution. If we have a phenomenon that occurs in the following form: an experience of an object while the object itself is absent, then that is precisely what the experience is, phenomenologically: a presence of experience and an absence of an object. To struggle with the problem of how an absent thing can affect us is to struggle with a long-standing philosophical bias: only that which is "real" has the power to affect us or to be the cause of something. What this simple intuition about imagination highlights for us is that, in addition to the imaginative object (however conceived, explicated, or 
clarified), there is a separate and distinct phenomenological category: the experience of the object. Thus, the phenomenological description of imagination ceases to be the appearance or presentation of unreal objects, and becomes instead the peculiar ability to have an affective experience of something without its presence. Therefore if we were to focus solely on how the object of imagination appears to us we will never be able to fully comprehend the totality of imaginative experience.

Husserl's treatment of the subject of fantasy and memory provides the framework for a clearer development of this distinct phenomenological category, "the experience of the object". In his personal transcripts, published in Husserliana XXIII and in English as Phantasy, Image Consciousness and Memory $^{1}$, Husserl addresses, in detail, problems regarding phantasy and places them in the broader context of his concept of experience. I want to focus on the specific parallel Husserl draws between the intentional character of memory and fantasy. Husserl asserts that while memory is a positing experience and fantasy is a non-positing experience, both are similar in that they appear as reproductions of primary experiences ${ }^{2}$. Both share the same kind of modification of the object, giving it a non-originary nature as experienced again. Memory naturally reproduces an actual past experience, but phantasy also has this indirect "reproductive" nature even though it does not need to refer to an actual past experience. In fantasy, a primary experience is always implicated, giving fantasy the phenomenological structure of "an experience of an experience"3. The object is given at a distance from consciousness and, in the gap created by this distance, the fictive experience is implied. Husserl here points out the fact that, in fantasy - as opposed to perception - the object is not experienced directly. There is a mediatory component present between consciousness and the object, and that mediatory component is the experience of the object.

It is important to note that when Husserl analyzed imagination he was also engaged in giving an account of the way the imaginative image appears. Husserl did not address imagination differently than Sartre and Casey in the respect that he too did not give the rightful importance to its affectivity and experiential presence. But I believe that Husserl noticed something very important and in need of further clarification. In fantasy, the image appears to us as distant and remote and is itself mediated by an experience. Even if we focus only at the way the object appears to us, just as Husserl does, we

\footnotetext{
${ }^{1}$ Husserl E., 2005.

${ }^{2}$ Ibid., p. 323-334.

${ }^{3}$ Ibid., p. 363-399.
} 
still find that the object itself undergoes a unique modification. The object points us away from itself, from its own appearance, and directs us to focus on the presence of its experience. In both the case of memory and fantasy, we intuit how it was or how it would be to experience something. Extending this scheme to imagination generally, I claim that imagination becomes a direct intuition of how it is to experience an object and not simply an intuition of an object in a possible mode (or nothingness). I believe, furthermore, that the isolation of this distinct phenomenological category in the case of imaginative experience enables me to now construct a new outline of the intentional structure of imagination, one that will include affectivity. This is because, the moment we can start speaking of "how it is to experience an object" we have entered the realm of affectivity.

In imaginative experience we have, on the one hand, the intuitive presence of how it is to experience an object - in our case, the child's experience of seeing a monster in his room. On the other hand, we have the absent, distant, protean nature of the imaginative object itself - in our case, the presence of the monster. It is clear that we can speak about the monster as an object presented to consciousness precisely because of the strong presence of the experience of the monster. The relation between the two is that the object appears, phenomenologically, as a kind of epiphenomenon, a "sideeffect" of how it is to experience that object. When I imagine a tree, I am not seeing a tree, I am experiencing myself as if I am seeing a tree. The direct intuition we have is not of this object but rather, of how it is to experience this object.

The quasi-observation of the tree itself is simply a byproduct of the direct intuition of how it is to experience the tree. It anchors the experience and makes it appear as though it is attached to "something" (even when this something is a no-thing). To clarify these schemata, it is essential at this point to bring the language of marginality and centrality to our discussion. When speaking of imaginative experiences, what stands at the center is the direct intuition of how it is to experience an object. The imaginative object arises, spontaneously, on the margins of the imaginative experience as a byproduct. When I refer to the center of the experience I am referring to the phenomenon that are experienced directly, for this is what defines the essence of the experience. I call something "central" if it is the case that altering it would alter the essence of the experience itself. I define the marginal contents of the experience as those intentional moments that appear epiphenomenally. The contents on the margins are present but alterable, and altering them need not change the experience in an essential way. 
The new phenomenological structure I am outlining gives a more specific meaning to the reproductive modification that Husserl describes in the case of both memory and fantasy. The object appears reproduced precisely because it refers us to something other than itself. The thing that it refers to is not a prior experience of the object, but just the experience of the object. Memory and fantasy are similar not because, like memory, fantasy implies a past experience, but because, like in fantasy, memory is an intuition of an experience and not an intuition of an object. In both cases, the modification involves the shifting aside of the object that appears, not as something present, but as a kind of an echo of its experience. So it will be more precise to say that memory is posited fantasy, rather than fantasy being neutralized memory. This new structure also explains why the imaginative object is impoverished, protean and spontaneously arising like a thought: it is not because, as Sartre asserts, in imagination we experience nothingness, rather it is precisely because the object is nothingness to the imagination. Now we can see why any further analysis of the imaginative object takes us further and further away from a systematic understanding of the affectivity of imaginative experience. The rich affectivity of imaginative experience is a direct result of the phenomenological intuition of how it is to experience an object, not of the imaginative object itself, which arises spontaneously on the margins.

The new structure I am presenting also gives us a new and robust way to distinguish phenomenologically between perception and imagination. In perception, the object appears in the center of the experience and is present in a total fashion, it is the thing experienced and the phenomena given to us, not a side effect in any way. On the margins, we have the way that I experience the object. In perception the presence of the object defines the experience. Sartre pointed out the infinitely rich nature of the perceptual object compared with the generally impoverished nature of the image ${ }^{1}$. This infinite richness of detail is understood here as the infinite central presence of the object, an object that necessarily includes infinite potentiality for further division into smaller objects we call details. The richness of the perceptual object is a product of its totally infinite objectivity. In imagination, the object appears epiphenomenally, on the periphery, while what stands at the center is the experience of the object itself. This revised view of the distinction between perception and imagination also makes it much easier to see why Sartre contrasted the imaginative object and the perceptual object in the way that he did. The imaginative object is nothingness, the perceptual object is rich with

${ }^{1}$ Sartre J.P., 2004, p. 9, 21. 
detail, but their opposing characteristics should not mislead us into making a false equivocation. Sartre wasn't wrong, he just compared the wrong things. The correct opposition to apply is what stands at the center of the perceptual experience versus what stands at the center of the imaginative experience.

This format offers us a purely transcendental explanation of how consciousness distinguishes imagination and reality solely through their mode of appearance. If the object is at the center of the experience, it is "taken seriously" and understood as real, and if it is only marginal in the experience it is "dismissed" and understood as non-existent. Furthermore, with this scheme, we can now see how both reality and non-reality, perceptual and imaginative, exist as two opposing poles on a spectrum. The marginality and centrality of the object can have intermediate states where the object can appear in the borderlines between the margins and the center and be hard to determine as fictive or real. Merleau-Ponty criticized Sartre's theory of imagination ${ }^{1}$ precisely for the way he treated the real and non-real as totally distinct and recognizable, while ignoring the many cases in which the line between real and unreal was not so clear, as in the case of optical errors and illusions.

\section{Imagination and value qualities}

With the preliminary sketch of our new phenomenological structure firmly in place, we can now embark on the work of clarifying and explicating the precise nature of this central feature of imaginative experience. It is important to stress that when we speak of the experience of experience or of the affective aspects of the experience, we are not talking about the affect itself, meaning emotions. There is a clear distinction between imagining and feeling. Imagination is indeed an experience that gives rise to emotions, but it is not emotion itself. I can imagine things without having any feelings, and still I am intuiting the experience of the object. So in order to understand exactly what it is we are intuiting when we imagine, we need to examine what would remain of the object's experience if we were to peel away the presence of the object itself. When I talk about the object, I am talking about the intentional object with all of its eidetic determinations and horizons, and this is what I am saying is marginalized in imagination. In his transcendental reduction, Husserl showed that we can ignore the transcendent reality of things and still not lose any attribute of their essence. The question becomes: What remains

${ }^{1}$ Merleau-Ponty M., 1968, p. 3-14, 63-64. 
of our experience if we reduce not only the reality of the object, but also the object itself?

And so we must ask: What appears in our field of intuitive experience in addition to objects? Every experience that we have always includes more than the actual encounter with the object or state of affairs. When I see a tree, feel happy, think about New York City or run on the beach, beside all the actual constituents of these experiences, the perception of the actual objects, the feelings and the thoughts, there is always another aspect that is constantly accompanying them - and that is, the direct intuition of their value. Accompanying every experience is an intuitive sense of the value-affective character of that experience. This value-affective character is not a reflective judgement, thought or emotion, it is given directly and intuitively with every object and experience. It is there as the flavor of the experience, an intuition of the experience's taste or worth. This sense of value is one and the same with the direct intuition of what it is like to experience this thing. For to experience a thing is to directly intuit the value laden meaning that this thing possesses.

The basic idea that we directly intuit a world of values is not new, it has already been addressed in some capacity by Husserl in section 27 of Ideas I, and I quote:

Moreover, this world is there for me not only as a world of mere things, but also with the same immediacy as a world of objects with values, a world of goods, a practical world. I simply find the physical things in front of me furnished not only with merely material determinations but also with valuecharacteristics, as beautiful and ugly, pleasant and unpleasant, agreeable and disagreeable, and the like. Immediately, physical things stand there as objects of use, the "table" with its "books", the "drinking glass", the "vase", the "piano", etc. These value-characteristics and practical characteristics also belong constitutively to the objects "on hand" as objects, regardless of whether or not I turn to such characteristics and the objects ${ }^{1}$.

I am specifically interested in the way in which Husserl suggests that we have direct intuitions of values in the same way we have direct intuitions of things ${ }^{2}$. Every object/thing (whether it be physical, psychic, a state of affairs

\footnotetext{
${ }^{1}$ Husserl E., 1998, p. 53.

${ }^{2}$ Setting aside what Husserl addresses as practical characteristics which have been dealt with extensively and exhaustively by Heidegger, Husserl hones in on a very peculiar aspect of the experience of things.
} 
or a concept) is accompanied by a direct intuition of its value ${ }^{1}$. We can further clarify these value characteristics by calling them the "affective form" of the experience. Now, at first glance, it may seem difficult or counterintuitive to create a separation between objects and their value. However, it is my contention that, in practice, we do in fact separate values and things regularly, so much so that it may be better to say that things are found inside values rather than values being discovered inside of things.

Let us take an example of a bride that has gone out to choose her wedding dress. Before going to the shop she knows that she is looking for a beautiful dress. She does not have yet a clear vision of how the dress will look, but she knows she wants the dress to be "classic and sophisticated". Choosing from a wide selection of dresses she looks for the one that she intuits to best suit her criteria. In this case we can see that the bride has a primary direct intuition of "beautiful", "classic" and "sophisticated" before she encounters the actual dress. It is clear her intuition of the value-quality is prior to her discovery of those value qualities in a particular dress. So we can see that objects and their affective-form, or value-qualities, can be separated phenomenologically as two different moments. In practice, we always encounter these two categories in a relationship, but in this relationship the objects have no primacy. The value-qualities have an autonomous presence of their own and, in practice, are often more dominant and present than the objects themselves. Sometimes the object is central and the value accompanies it marginally, and sometimes it is the other way around. Every experience of an object is accompanied by an explicit or implicit value, and every intuition of a value implies an object or objects that are associated with

\footnotetext{
${ }^{1}$ In Ideas II Husserl deals extensively in his own way with the phenomenological meaning of value qualities. See Husserl E., 1989, p. 6-27, 194-200, 223-231. Husserl understands values as rising in the noetic act of valuing, which is a direct act of active judgement of the given noema. Accordingly, the intuitive presence of the value that is given directly as part of the noema itself in other noetic acts, is part of a kind of secondary noema which already includes in it the past noetic acts of valuing. This description given by Husserl is problematic and in need of further investigation and clarification that will not be carried out here for the sake of presenting a whole and coherent picture of imagination, and will be dealt in a separate paper that is currently a work in progress. The analysis that I suggest below does not exactly contradict Husserl's own analysis but rather tries to clarify it. I argue that this "past act of valuing" changes its nature extremely when it becomes part of the secondary noema and does not appear as an act at all, but rather as the experiential-affective form of the object.
} 
it and can fulfill it. The important point is that we can focus our intention on either of the two separately.

My claim is that when we imagine something of any sort we actually intuit exactly these value qualities, or what I call "the affective form of the object". These value-qualities that can be intuited without the presence of an object, as I have just shown, are what remains of the experience of the object when we subtract the object's actual presence. When I see Paris in a film, Paris is not present in any way, I cannot see it, touch it or smell it at all, and all that I actually see are lights flashing on a screen. But I let these lights and colors manipulate me to imagine Paris and experience as if I am seeing this city. Paris is not present to me in any way - having no ability to sensually experience it, it is nothingness. And yet, Paris is present in a very direct way. I cannot see it or touch it, but I experience its beauty and its special flavor and style intuitively and immediately and directly.

These intuitive and directly given value qualities are what stand in the center of imagination, and they are what I describe as "the experience of the object". The direct intuition of value qualities is exactly what remains of the experience when the object itself is missing. Moreover, these value-affective qualities are the content of imagination. There is matter experienced here, but it is not the marginal, thought-like appearance of the object. The hyletic component that gives the act of imagining its intuitiveness is the presence of the value-affective qualities. It is through imagination that a self-same object becomes something completely distinct, specifically because the imaginative value structure through which we perceive that self-same object is utterly distinct. An act of terror can be experienced as horrifying and evil, but it can also be experienced, intuitively, as holy and sublime. These are not different reflective judgments of the same object but rather two directly differing intuitive experiences of value that cannot be reduced to thought.

The heart of my argument is that value-qualities are never actually perceived even though they are intuited directly. They are always imagined and only objects are perceived. Imagination's own meaning, sui generis, is the direct intuition of value-quality. Therefore, imagination is present in all of our experiences because all of our experiences are accompanied by direct imaginative intuition of their value. In the intuition of the value there is a marginal appearance of the object that is associated with it, and in the intuition of the object there is a marginal appearance of its value.

Take a moment and actively perceive the room in which you now sit. You will notice that at the center of your perceptual experience are the objects or persons in the room, its physical details and so on. These are the heart of the experience because they are present in an undeniable way. On 
the margins of this perceptual experience are the value qualities you see in this state of affairs: is it boring, exciting, sophisticated or peaceful? These value-qualities exist on the margins because you are intuitively aware of their subjective quality. You have the ability to shift your attention and focus on other aspects of what is happening, and by this radically change your experience. Sometimes these value qualities change by themselves; what was peaceful can become disturbing. Yet the details of the room remain solid and unchanging by these shifts. These changes of attitude do not change the perceptual experience at all. It remains solidly identified with the consistency of the objects. We perceive the same thing but experience it in a different way. In imagination, on the other hand, the value-nature of the imaginative object is at the center of the experience. These value-qualities actually appear as more solid than its actual features. Try to imagine a view and you will find that the general attitude to this view is a lot clearer than any detail of the image. It is, first and foremost, beautiful or scary, joyful or sad and only then is it detailed in a specific way. The details of this image can shift but we will not see it as a change of experience until the affective aspect will change. Imagining a pastoral field stays the same experience if there are birds there or not, if there is a farm-house on the horizon or not, or if the field is a field of wheat or barley or flowers. The objects keep changing in an undetermined fluidity that does not disturb our imaginative experience, but is rather a part of its nature. But if, however, the experience of the field becomes frightening and upsetting, the imaginative experience will totally and abruptly change.

I believe that this phenomenological structure also helps us explain exactly why we are so drawn to and tempted by virtual and imaginative experiences. In the case of virtual or imaginative experience, we are focusing not on objects but on their affective value, which is exactly what makes them interesting to us in the first place. If we were to understand imagination through its objects only, which give themselves as nothingness and absence, it is difficult to explain the strong positive appeal imaginative experience has for us. We are drawn to imagination and virtuality not as an escape (although it often has that element), but rather because they bring us directly into contact with the affective-value quality of things. These value-affective qualities are what we seek in things and they constitute our intimate relationship of value with the world. Therefore, when we have a purely imaginative experience, we stand in a direct relationship with all the aspects that make something affectively important to us. If we take for instance a character in a movie, its imaginative presence is always less rich in detail and presence than an actual person, but on the other hand, the value-qualities we see in him are a lot more distinctive and present than a real person. The character is a 
construct of value qualities because he is imaginative, while a real person always exceeds all the value constructs we may see in him. In the case of a film, the intuitive appeal is precisely that we are able to experience the character as a pure relation of value without all the distracting interruptions of his actual existence.

Returning now to the difference between imagination and perception, it is not simply that they have an opposite phenomenological structure. Values and objects are two essential moments of experience and they stand in a dialectical relationship with one another. Values and objects are two kinds of intentional attentions that can be focused on creating different relations between them. We intensively analyze the material components of the objects, looking for the structures that construct the world of things, but things are not all that inhabit our experience. Our world is as much a world of values as it is a world of things. Therefore, our world is constituted not just in perception and thought but also in imagination, and therefore, this world possesses an imaginative structure no less than it possesses scientific facts.

An important consequence of this analysis of imagination is the understanding that value qualities are not found in objects inherently but are only associated with them. The value qualities seen in objects are the object's "imaginative nature", and they subsist in the objects through imaginative association and expectation. When imagining an object I am revealing the way I expect the object to affect me. This connection between the object and value does not occur when we intend the object itself, rather the connection between object and value occurs through the mediatory intention of how it is, or how it would be, to experience that object. What this means is that we can effect a change in the value nature of an object, without altering the object itself in any way, but rather, by changing its imaginative structure. A perfect example is found in a technique known as rebranding. If you want to rebrand Pepsi in relation to Coca-Cola, you change the imaginative nature of Pepsi. This is what Pepsi did in 1984 with its Michael Jackson "Pepsi Generation" commercial $^{1}$ linking youth, ethnicity, and excitement - all imaginative qualities, as an essential part of the associative value nature of Pepsi. Not only was Pepsi brand significantly altered but the value of Coke was also transformed by this move: if Pepsi was youth and energy, Coke was becoming old and dull. Of course, rebranding is only one example, it is a specific application of the way imagination functions, with its centrality based on direct intuition of value-qualities. The key is that in imagination we are not

\footnotetext{
${ }^{1} \mathrm{https}: / / \mathrm{www}$.youtube.com/watch?v=po0jY4WvCIc
} 
dealing with objects, only with value-qualities. The objects appear but only marginally, and only insofar as they are anchored by their unique value structure.

\section{Conclusion}

I have suggested here a phenomenological analysis of imagination that reveals the experience of value and its association with objects at its center. The result of these peculiar connections between objects and value, that vary from culture to culture and from individual to individual, is the value structure of the world. The value-laden way in which the world is structured for us is essentially what guides all of our judgements. I term these value structures imaginative structures, as the relationship between values and objects is always, as I have tried to show, constituted in imagination. Imaginative structures are a new tool for analyzing the way objects are valued and experienced in different contexts. Understanding that things values are their imaginative nature allows us to reflect on the diverse ways in which these structures vary. Human thought, by nature, is unaware of its own imaginative structure and views the value infrastructure it sees in the world as actual (as inherent in the objects themselves). Naturally, the values that constitute the world of an "other" that contradict my own values are "wrong". These opposing value structures are regarded as non-actual and are, at best, deemed errors and at worst deemed willful and evil manipulation. The paradigm of imaginative structures understands that there is no transcendent value in the things themselves. Value is always a specific way of "dreaming things". This consciousness can open a path for deeper intercultural understanding and communication as well as pave the way for analyzing various imaginative relations through differing value structures. Imaginative structures name the specific value constructs and configurations that shape human experience and have the potential to be used in a wide range of interdisciplinary research in the areas of culture, politics, gender, art, social theory and psychology to name a few.

It is my hope to continue the research of imaginative structures specifically in the context of ethics. If it is the case, as I have suggested, that there is no essential relationship between things and values, but rather that the value of things comes from the imaginative structure that things inhabit, ethical discourse must turn to deal more with the way value is constructed than with the way specific objects are valued. 


\section{References}

Bernet Rudolph, "Unconscious Consciousness in Husserl and Freud", Phenomenology and Cognitive Sciences, Volume 3, 2002, p. 327-351.

Casey Edward. S., "Sartre on Imagination", in P. A. Schilpp (ed.), The Philosophy of Jean Paul Sartre, La Salle, Illinois, Open Court Publishing, 1981, p. 167-178.

Casey Edward. S., Behnke E. A. \& Kanata S., "Imagination", in Encyclopedia of phenomenology, Dordrecht, Springer, 1997, p. 340-344.

Casey Edward. S., Imagining - a Phenomenological Study, Indiana, Indiana University Press, 2000.

Clayton Cam, "The Psychical Analogon in Sartre's Theory of the Imagination", Sartre Studies International, 7(2), 2011, p.16-27.

Husserl Edmund, Ideas Pertaining to a Pure Phenomenology and to a Phenomenological Philosophy - First Book, Engl. tr. Kersten F., The Hague, Martinus Nijhoff Publishers, 1998.

Husserl Edmund, Ideas Pertaining to a Pure Phenomenology and to a Phenomenological Philosophy - Second Book, Engl. tr. Rojcewicz R. \& Schuwer A., Dordrecht, Kluwer Academic Publishers, 1989.

Husserl Edmund, Phantasy, Image Consciousness and Memory (1898-1925), Engl. tr. Brough J., Dordrecht, Springer, 2005.

Jansen Julia, “On the Development of Husserl's transcendental Phenomenology of Imagination and its use for Interdisciplinary Research", Phenomenology and Cognitive Sciences, Volume 4, 2005, p. 121-132.

Merleau-Ponty Maurice, The Visible and the Invisible, Engl. tr. Lingis A., Evanston, Northwestern University Press, 1968.

Ricoeur Paul, "Sartre and Ryle on Imagination", in P.A. Schilpp (ed.), The Philosophy of Jean Paul Sartre, La Salle, Illinois, Open Court Publishing, 1981.

Sartre Jean Paul, Imagination: a Psychological Critique, Michigan, 1972.

Sartre Jean Paul, The Imaginary, Engl. tr. Webber J., London and New York, Routledge, 2004. 